\title{
NANO-BASED SURFACE TREATMENT EFFECTS ON SWELLING, WATER SORPTION AND HARDNESS OF WOOD
}

\author{
H. Turgut Sahin ${ }^{1}$, George I. Mantanis ${ }^{2}$
}

\begin{abstract}
Untreated and nano-based compound treated chestnut, wild cherry, fir, and black pine wood samples were immersed in water at four different temperature levels. It was found that the nano-based compound was a very effective agent for lowering both the initial and maximum equilibrium transverse swelling of wood. However, the latter were found to have similar trends as the initial swelling properties. The surface treatment appeared not to improve the maximum water absorption. The highest average activation energy was calculated for chestnut $(23.1 \mathrm{~kJ} / \mathrm{mole})$, followed by pine $(20.2 \mathrm{~kJ} / \mathrm{mole})$, cherry $(18.1 \mathrm{~kJ} / \mathrm{mole})$, and fir $(16.2 \mathrm{~kJ} / \mathrm{mole})$. However, the nano-based treatment resulted in a small increase in activation energies of all wood species. It was found that absorption of water into wood as well as increasing temperature had a lowering effect on shore D hardness.
\end{abstract}

Keywords: Nanotechnology compound, wood swelling, transverse direction, water sorption, activation energy, surface hardness.

\section{INTRODUCTION}

Wood as a lignocellulosic material has for hundreds of years played a major role as an element in infrastructures and raw material for valuable products. Even today wood is valued as a renewable resource in a wide range of industrial applications. However, solid wood is heterogeneous, hygroscopic, and susceptible to biological degradation by fungi, insects etc. Especially, its dimensional increase (swelling) is a major problem, and difficulties frequently occur when the relative humidity of the air surrounding the wood changes (Mantanis 1994, Berry and Roderic 2005). Since wood properties are highly related to amount of water in it, understanding wood-water interactions therefore is a key research area for all uses of wood-based materials.

Interactions between wood and water have been a topic of research for many years. Several studies have been carried out and theories have been considered on the wood-water interaction (Siau 1984, Simpson 1993, Mantanis et al. 1994).

Water can be directly attached hydrogen bond to wood through hydroxyl groups and indirectly through modified water structure (Berry and Roderic 2005, Rowell 2005). Water molecules may enter and transfer from amophous regions and primarily being hydrogen bonded to the hydroxyl groups in the lattice (Siau 1984). This requires a suitable space and energy level to allow sorption to occur.

Due to the interaction between large cellulose chains and small polar water molecules, a wood-water system at equilibrium state may be considered as a non-ideal binary solution. In such a system, adsorbed water molecules in wood are considered to be mobile. However, it is important to notice that the adsorbed water is relatively stable around the sorption sites due to the chemical forces.

\footnotetext{
${ }^{1}$ Suleyman Demirel University, Faculty of Forestry, Dept. of Forest Products Engineering, 32260, Isparta, Turkey

${ }^{2}$ Technological Education Institute of Larissa, Branch of Karditsa, Department of Wood and Furniture Design and Technology,

Wood Technology Lab, 43100, Karditsa,Greece.E-mail mantanis@teilar.gr

Corresponding author: sahin@orman.sdu.edu.tr

Received: 05.08. 2010 Accepted: 01.12. 2010
} 
A number of studies on sorption theories relating to wood-water system have been proposed in the literature (Mantanis et al. 1994, Ishimaru and Lida 2001, Albert et al. 2005, Sahin 2007). However, most of the approaches provide some equations for correlating data through curve fitting and ascribe this to the complexity of the polymeric structure of wood. A well-stated approach developed to describe wood swelling by water and organic liquids is that of Mantanis (1994), which has been employed by several researchers (Rowell 2005, Sahin 2007 and 2008a).

A number of approaches have been used so as to reduce the swelling of wood. The varying moisture content of wood results in dimensional and conformational instability, which can compromise the performance of other materials combined with wood, such as adhesives and surface coatings. Until recently, these shortcomings were addressed by impregnating wood with appropriate hydrophobes and other chemicals (Kumar 1994, Rowell 2005, Hill 2006). In addition, wood can be modified chemically or thermally so that selected properties, such as dimensional stabilisation, be improved in a more or less permanent fashion (Hill 2006).

An option to further reduce the swelling of wood in end-uses is to exploit the solutions that nanotechnology can offer today. Employing nanotechnology on wood can result in a next generation of products having hyper-performance and superior service ability when used in severe environments, since it is well known that the cell wall of wood exhibits porosity of molecular scale dimensions due to the partial filling of space between the cellulose microfibrils by lignin and hemicelluloses (Wegner et al. 2005, Wegner and Jones 2006). Due to their small size such nanoparticles can deeply penetrate into the wood, effectively altering its surface chemistry and resulting in a high protection against moisture (Mantanis and Papadopoulos 2010a, 2010b).

The aim therefore of this study was to examine the influence of a nano-based surface compound on several wood species when immersed in water by measuring average transverse dimensional changes, water absorption and surface hardness. Through this study, we hope to bring light on how the wood-water interaction changes during swelling and how to monitor these changes through the use of conventional measurements.

\section{MATERIALS AND METHODS}

Four different wood species, two softwoods and two hardwoods, were used in these experiments. Chestnut (Castanea sativa) and wild cherry (Prunus avium) were supplied from the Black sea region of Turkey, while fir (Abies cephalonica) and black pine (Pinus nigra) were supplied from Pindos, Grevena area, of Greece. Five samples from each species were cut into $20 \mathrm{~mm}$ (tangential) $\times 20 \mathrm{~mm}$ (radial) $\times 15$ $\mathrm{mm}$ (longitutinal) blocks from sapwood and oven-dried for 48 hours at $50^{\circ} \mathrm{C}$ prior to experiments.

By measuring dry volumes and weights of fir, black pine, cherry, and chestnut blocks densities of $410 \mathrm{~kg} / \mathrm{m}^{3}, 520 \mathrm{~kg} / \mathrm{m}^{3}, 520 \mathrm{~kg} / \mathrm{m}^{3}$, and $600 \mathrm{~kg} / \mathrm{m}^{3}$ were estimated, respectively.

A new nano-based compound, namely SurfaPore ${ }^{\mathrm{TM}} \mathrm{W}$, was supplied by NanoPhos SA(Lavrio, Greece) and selected in order to investigate the potential of improving thickness swelling (TS) of the wood samples. SurfaPore ${ }^{\mathrm{TM}} \mathrm{W}$ is a water based formulation designed to harness the power of nanotechnology in order to preserve absorptive wooden surfaces. The formulation consists of three different nanoparticle sizes, specially designed to penetrate into the wood mass. The finest nanoparticles are intended to penetrate through the capillaries and bond with the hydroxyl groups of the cellulose content. The larger nanoparticles are intended to penetrate at the appropriate depth and react with the wood polymers. Finally, the formulation is completed by a nano-emulsion of paraffin that is intended to ensure surface protection. This nanocompound is composed of metal oxides; namely, titanium dioxide and zinc oxide. The physical and chemical properties of this nano-based compound can be found elsewhere (Mantanis and Papadopoulos 2010a, 2010b). 
The wood samples were immersed in distilled water at four different temperatures, that is, 23,50 , 75 , and $100^{\circ} \mathrm{C}\left( \pm 5^{\circ} \mathrm{C}\right)$, respectively. The average initial $(5 \mathrm{~min})$ and average maximum equilibrium transverse directional swelling properties were determined, waited till there was no more swelling. Wood swelling in the radial and tangential direction, usually called the transverse direction, is always much higher than that in the longitudinal direction and usually the former is taken into consideration for monitoring dimensional changes. Hence, transverse directional swelling of each wood species was calculated as the average of the radial and tangential swelling values.

After maximum equilibrium swelling measurements, wet samples were air-dried $\left(23 \pm 2^{\circ} \mathrm{C}\right)$ for $48 \mathrm{~h}$ and then they were dried in an oven for $24 \mathrm{~h}$ at $105^{\circ} \mathrm{C}\left( \pm 3^{\circ} \mathrm{C}\right)$ for the determination of the final weight and hardness properties.

Rowell and Ellis (1977) stated that wood treated with chemical agents may impart dimensional stability in water. However, they suggested that it might be better to determine dimensional stability of wood after the first soaking cycle. Further soaking cycles could give misleading results because the first soaking cycle removes most of the agents that have bound to wood cell wall constituents (Mantanis and Papadopoulos 2009b). Therefore, after the first soaking cycle of the samples, the effects of nanoparticulate treatments on dimensional changes were measured, and these were compared with the untreated samples.

All swelling measurements were made with a Mitutoyo-500 caliper $( \pm 0.02 \mathrm{~mm})$. Using the methodology developed by Mantanis (1994) and Sahin (2007), the activation energy of wood was calculated by using the Arrhenius equation. A complete description of the Arrhenius equation as well as the calculation methodology of the wood activation energy (EA) from an Arrhenius plot is given elsewhere (Mantanis 1994). The average transverse activation energy of wood species was measured by using the average of both tangential and radial EAs.

For measuring surface hardness properties of wood, a Shore hardness (Scale D) instrument was utilised. The surface hardness properties of both untreated and nano-based compound treated samples were measured at wet stage, higher than the fiber saturation point, and at dry stage (air-dry), seperately. For each direction, five measurements were made. The average surface Shore-D hardness properties were calculated by using the following equation:

$$
\text { Shore-D Hardness }(\text { Degree })=(\text { Tangential hardness }+ \text { Radial hardness }) \div 2
$$

\section{RESULTS AND DISCUSSION}

Table 1 shows the average swelling in the transverse direction of untreated and nano- based compound treated wood at varying temperatures and times. The measurements showed that the nano-based compound is an effective agent for lowering the initial swelling rate of wood. However, the greatest initial swelling improvement was determined at $23^{\circ} \mathrm{C}$ (room temperature) for fir $(56.1 \%)$, followed by pine $(47.6 \%)$, chestnut $(30.7 \%)$, and cherry $(20.4 \%)$. No statistical analysis was carried out in these results. Increasing the temperature typically resulted in a higher initial swelling rate in both untreated and treated samples. This is probably related to wood-water interactions, since reaction mechanism in the wood-water system primarily depends on the chemical interactions between those; it is probable that increasing kinetic energy in wood-water system results in easier accessibility of water to the bulk of wood.

The maximum equilibrium transverse swelling properties of wood were found to have similar trends as the initial swelling properties; that is, increasing water temperature usually influenced more swelling for both untreated and nanocompound treated samples. However, the nanocompound treatment resulted in some improvement effect on wood species at different temperature levels. The greatest maximum 
equilibrium transverse swelling improvement was determined for fir at $100^{\circ} \mathrm{C}(13.2 \%)$, for pine at $50^{\circ} \mathrm{C}$ $(11.1 \%)$, for cherry at $75^{\circ} \mathrm{C}(32.1 \%)$ and for chestnut at $100^{\circ} \mathrm{C}(15.9 \%)$, respectively. It is assumed that the nano-based compound treatment acts on the wood-water interaction possibly with its molecules reducing the surface energy, hence, promoting the dimensional stability with water. However, when enough energy had been generated in the wood-water system such as, increasing temperature and/or reaction time, it affected the broken nanoparticulate-wood bonds, resulting in an increase in volume (swelling). It has already been well demonstrated that increasing temperature can have detrimental effects on wood surface agents (Sahin 2008b). The result found with the nano-based compound treatment in this study is in very good agreement with similar results found in the literature (Mantanis 1994, Sahin 2008b, Mantanis and Papadopoulos 2010b).

Table 1. Average Transverse Swelling of Wood

\begin{tabular}{|c|c|c|c|c|c|c|c|c|}
\hline $\begin{array}{c}\text { Temperature } \\
\left({ }^{\circ} \mathbf{C}\right)\end{array}$ & Fir & \multicolumn{2}{c|}{ Pine } & \multicolumn{2}{c|}{ Cherry } & Chestnut \\
\hline \multicolumn{8}{|c|}{ Transverse Swelling after 5 minutes (\%) } \\
\hline & Unt. & Trt. & Unt. & Trt. & Unt. & Trt. & Unt. & Trt. \\
\hline 23 & 2.28 & 1.46 & 1.34 & 0.84 & 1.32 & 1.05 & 1.56 & 1.08 \\
\hline 50 & 3.2 & 2.9 & 1.8 & 1.35 & 1.65 & 1.34 & 1.8 & 1.17 \\
\hline 75 & 3.73 & 3.63 & 2.0 & 1.67 & 1.78 & 1.51 & 2.43 & 1.92 \\
\hline 100 & 5.2 & 4.48 & 2.4 & 2.05 & 2.21 & 1.77 & 2.89 & 2.12 \\
\hline \multicolumn{8}{|c|}{ Transverse Maximum Equilibrium Swelling (\%) } \\
\hline 23 & 4.17 & 4.03 & 6.63 & 5.29 & 5.5 & 5.2 & 4.89 & 4.48 \\
\hline 50 & 5.3 & 4.61 & 6.6 & 5.87 & 5.52 & 5.50 & 4.98 & 5.39 \\
\hline 75 & 5.1 & 4.73 & 5.96 & 5.54 & 6.71 & 4.56 & 4.93 & 5.13 \\
\hline 100 & 5.96 & 5.14 & 6.63 & 6.2 & 6.07 & 5.47 & 6.29 & 5.29 \\
\hline
\end{tabular}

Figure 1 shows comparatively the average activation energies of woods in the transverse direction. The highest average EA was calculated for chestnut $(23.1 \mathrm{kj} / \mathrm{mole})$, followed by pine $(20.2 \mathrm{kj} / \mathrm{mole})$, cherry $(18.1 \mathrm{kj} / \mathrm{mole})$, and fir $(16.2 \mathrm{kj} / \mathrm{mole})$. Although a little lower EAs were calculated for cherry, which is a hardwood with a density equal to that of black pine, these results are not surprising; a number of researchers have already reported strong correlations between swelling, density, and wood chemical constituents that are closely relating to wood swelling (Mantanis 1994, Rowell 2005, Sahin 2007, Sahin 2008a). Nevertheless, the wood-water interaction is a phenomenological issue and cannot be affected by single properties (e.g., wood density). Hence, anatomical features and chemical constituents (i.e., extractives) have also considerable influence on wood swelling (Berry and Roderic 2005, Rowell 2005, Sahin 2007).

Moreover, it appears that nano-based compound treatments yielded increased EAs of wood. This means that nano-based compound treated samples swell more slowly and exhibit lower transverse swelling. The results shown for initial and maximum equilibrium transverse swelling properties of wood (Table 1) support this finding. The maximum EA was observed with nanocompound treated fir $(37.3 \mathrm{kj} /$ mole), followed by nanocompound treated black pine $(28.7 \mathrm{kj} / \mathrm{mole})$, nanocompound treated chestnut (26.4 kj/mole), and nanocompound treated cherry (19.2 kj/mole), respectively. 


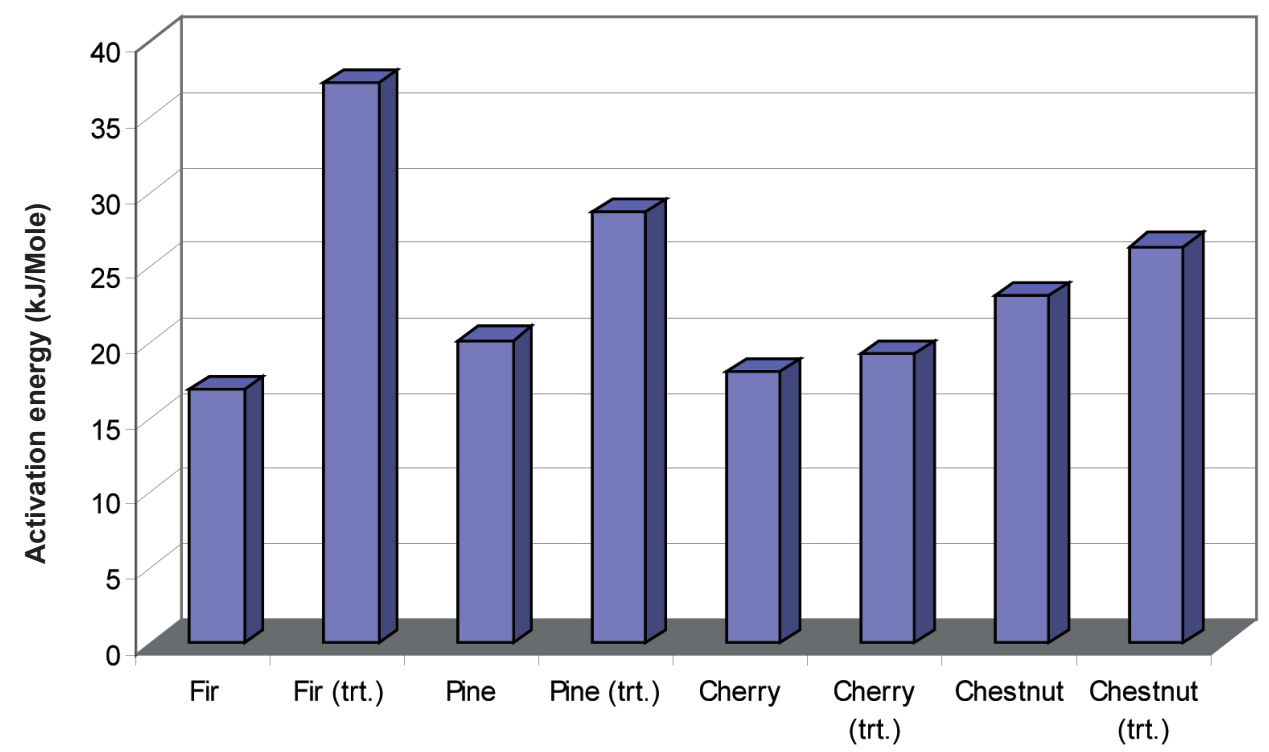

Figure 1. Transverse average activation energies of untreated and nanotreated wood species

The maximum water absorption of untreated and nano-based compound treated samples at four temperature levels are shown in figure 2. As expected, there was a correlation between temperature and water absorption for both untreated and nanocompound treated wood material. It was found that increasing temperature increased water sorption of both untreated and treated wood (Figure 2). For fir, the maximum water absorption occured at $100^{\circ} \mathrm{C}$ (approx. 52.1\%), much higher than that at room temperature. However, the maximum water absorption for pine, cherry and chestnut was found to be at $75^{\circ} \mathrm{C}$, that is, approx. 53\%, 38\% and 35\% higher than that observed at room temperature, respectively.

Interestingly, the nano-based compound treatment appeared not to improve the maximum water absorption of wood. This is somewhat surprising, considering that it were observed lowering swelling properties and decreasing swelling rates (increasing EAs) for the same species. However, nanoparticulatetreated samples showed higher water absorption at higher temperatures. The highest water absorption for nano-based compound treated material was found to be $131.1 \%$ for fir at $100^{\circ} \mathrm{C}$, followed by $88.6 \%$ for chestnut, $80.4 \%$ for cherry, and $63.2 \%$ for pine at $75^{\circ} \mathrm{C}$. The increase in the water absorption of wood species with the increase in temperature suggests a chemical reaction mechanism occurring during the water-wood interaction, but there was no specific correlation between swelling and water absorption whatsoever. It is likely that the wood's chemicals were modified with increasing temperature and affected the creation of more surface area for water molecules, especially in the cases of lignin and water-soluble extractives, which can be modified by the heat. Similar results have been reported for several species by Mantanis et al. (1995) and Sahin (2007, 2008a). 


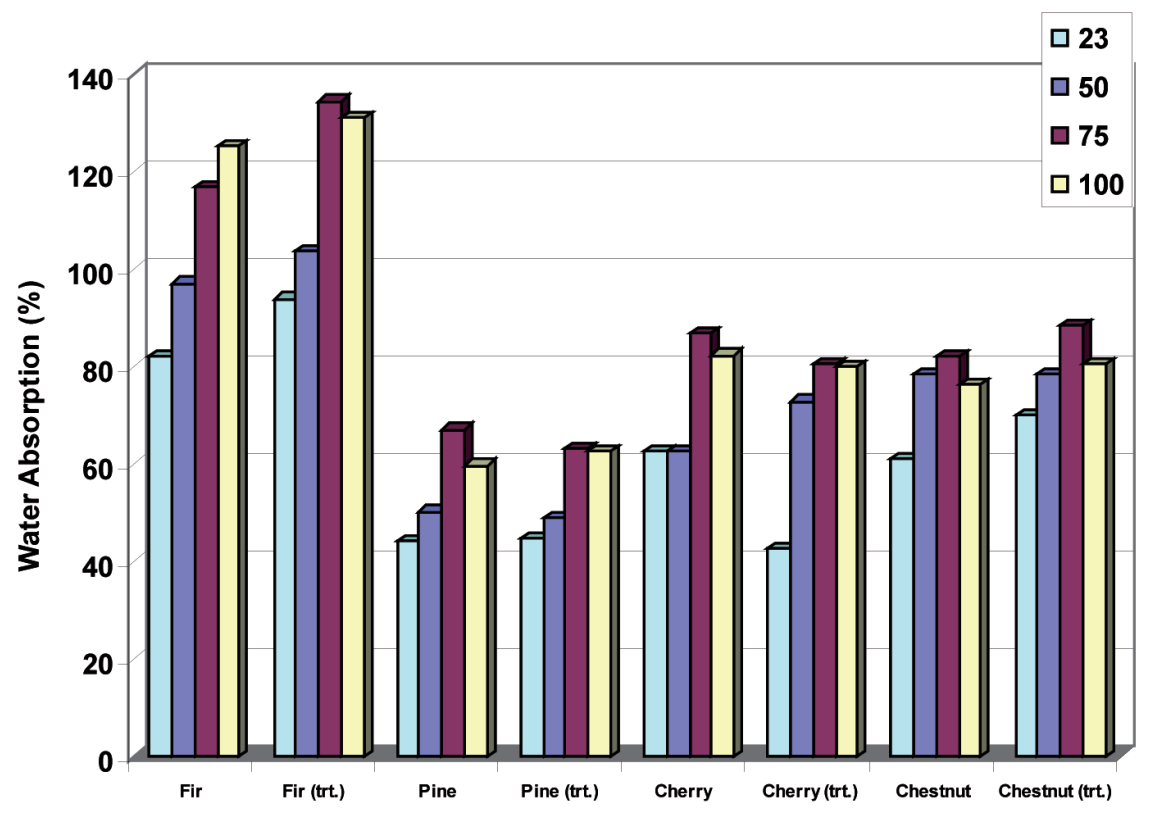

Figure 2. Water absorption of untreated and nano-based compound treated wood at different temperatures

Comparative results of the surface hardness of untreated and nano-based compound treated wood, above the fiber saturation point, at four temperature levels, are shown in Table 2. It was realised that absorption of water into a hydrophilic polymer (e.g., wood) showed considerably lowering effects on Shore D hardness of wood. It was found to lower the Shore-D hardness by 19, 16, 10, and 9 degrees at room temperature, for pine, fir, chestnut, and cherry, respectively, as compared to control samples. In addition, the temperature increase had a further lowering effect on shore D hardness. This was rather expected, because water can act as a plasticizer and it is well known that increasing temperature can further have plasticizing/softening effects, as shown in this work. Interestingly, the nano-based compound treatment typically lowered the Shore D hardness properties of wood by a few points under similar conditions. It is suggested that the nanocompound can lower the surface energy, hence promoting the dimensional stability of wood. However, this is not enough for lowering water absorption as well as improving surface hardness.

Table 2. Average Transverse Shore-D Hardness of Woods above the FSP

\begin{tabular}{||c|c|c|c|c|c|c|c|c||}
\hline \hline & Fir & $\begin{array}{c}\text { Fir } \\
\text { (trt.) }\end{array}$ & $\begin{array}{c}\text { Black } \\
\text { pine }\end{array}$ & $\begin{array}{c}\text { Black } \\
\text { pine } \\
\text { (trt.) }\end{array}$ & Cherry & $\begin{array}{c}\text { Cherry } \\
\text { (trt.) }\end{array}$ & Chestmut & $\begin{array}{c}\text { Chestnut } \\
\text { (trt.) }\end{array}$ \\
\hline Cont. & 51 & 40 & 66 & 58 & 65 & 63 & 66 & 63 \\
\hline 23 & 35 & 33 & 45 & 39 & 56 & 51 & 56 & 52 \\
\hline 50 & 35 & 28 & 41 & 39 & 58 & 50 & 56 & 50 \\
\hline 75 & 33 & 34 & 41 & 38 & 53 & 50 & 53 & 50 \\
\hline 100 & 33 & 33 & 42 & 40 & 53 & 53 & 54 & 53 \\
\hline
\end{tabular}


Table 3 shows comparative results for the surface Shore-D hardness of untreated and nanocompound treated wood species after being immersed in water and air-dried. It was found that the surface Shore-D hardness of wood increased after drying in the air. However, increasing treatment temperature resulted in higher Shore-D hardness. Like previous findings (Table 2), the treated samples typically had lower Shore-D hardness as compared to untreated samples under similar conditions. The largest Shore-D hardness decrease of nanocompound samples was found to be 6 degrees for fir at $50^{\circ} \mathrm{C}, 8$ degrees for pine at $23^{\circ} \mathrm{C}, 5$ degrees for cherry at $50^{\circ} \mathrm{C}, 75^{\circ} \mathrm{C}$ and $100^{\circ} \mathrm{C}$, and 3 degrees for chestnut at $75^{\circ} \mathrm{C}$.

It is clear that the nanocompound used was not an effective agent for improving water absorption and surface hardness of wood at either above fiber saturation point, or after air drying. This is somewhat surprising considering the observed improvements in dimensional stability. However, this observed variability indicates that the types of wood species -although they might be chemically and anatomically different- are sufficiently similar to allow a consistent surface modification with water.

Table 3. Average Transverse Shore-D Hardness of Immersed in Water and Air-Dried Wood

\begin{tabular}{||c|c|c|c|c|c|c|c|c||}
\hline \hline & Fir & $\begin{array}{c}\text { Fir } \\
\text { (trt.) }\end{array}$ & $\begin{array}{c}\text { Black } \\
\text { pine }\end{array}$ & $\begin{array}{c}\text { Black } \\
\text { pine } \\
\text { (trt.) }\end{array}$ & Cherry & $\begin{array}{c}\text { Cherry } \\
\text { (trt.) }\end{array}$ & Chestnut & $\begin{array}{c}\text { Chestnut } \\
\text { (trt.) }\end{array}$ \\
\hline 23 & 48 & 47 & 66 & 58 & 66 & 68 & 68 & 68 \\
\hline 50 & 53 & 47 & 64 & 60 & 73 & 68 & 71 & 72 \\
\hline 75 & 53 & 48 & 67 & 60 & 73 & 68 & 73 & 70 \\
\hline 100 & 54 & 51 & 66 & 63 & 69 & 64 & 69 & 68 \\
\hline
\end{tabular}

Lignocellulosics have been studied regarding Shore-D hardness by a number of researchers (Patil et al. 2000, Magalhaes and da Silva 2004, Misha and Naik 2005). Increasing Shore-D hardness has been exhibited with styrene-treated Caribbean pine and maleic anhydride-treated fiber composites (Magalhaes and da Silva 2004, Misha and Naik 2005). However, Patil et al. (2000) reported that moisture absorption had a detrimental effect on the mechanical properties of the wood-polymer composites (e.g., Shore-D hardness).

\section{CONCLUSIONS}

Surface treatment with a nano-based compound was found to be effective for lowering initial and maximum equilibrium average transverse swelling of four wood species. However, it was not proven an effective agent for improving water absorption and surface hardness of woods at either above fiber saturation point or in the case of air-dried wood. It is likely that this particular nano-based compound can lower the surface energy, hence promoting the dimensional stability of wood. However, this is not enough for lowering the water absorption as well as increasing the surface hardness.

\section{REFERENCES}

Albert, J.; Fotsing, M.; Tchagang, C. W. 2005. Experimental determination of the diffusion coefficients of wood in isothermal conditions. Heat Mass Transfer 41: 977-980.

Berry, S. L.; Roderick, M. L. 2005. Plant-water relations and the fibre saturation point. New Phytologist 168: 25-37.

Hill, C. A. S. 2006. Wood Modification-Chemical, Thermal and Other Processes. John Wiley and Sons Ltd., West Sussex, UK 
Ishimaru, Y.; Lida, I. 2001. Transverse swelling behavior of hinoki (Chamaecyparis obtusa) revealed by the replica method. J. Wood Sci. 47: 178-184.

Kumar, S. 1994. Chemical modification of wood. Wood and Fiber Sci. 26(2): 270-280.

Magalhaes, W. L. E.; da Silva, R. R. 2004. Treatment of Caribbean pine by in situ polymerization of styrene and furfuryl alcohol. J. Applied Polymer Sci. 91(3): 1763-1769.

Mantanis, G. I. 1994. Swelling of lignocellosic material in water and organic liquids. Ph.D. Thesis, University of Wisconsin-Madison, Wisconsin, USA

Mantanis, G. I.; Young, R. A.; Rowell, R. M. 1994. Swelling of wood, Part 1. Swelling in water. Wood Sci. Technol. 28: 119-134.

Mantanis, G. I.; Papadopoulos, A. N. 2010a. Reducing the thickness swelling of wood based panels by applying a nanotechnology compound. Eur. J. of Wood and Wood Prod. 68: 237-239.

Mantanis, G. I.; Papadopoulos, A. N . 2010b. The sorption of water vapour of wood treated with a nanotechnology compound. Wood Sci. Tech. 44 (3): 515-522.

Misha, S.; Naik, J. B. 2005. Mechanical properties of wood polymer composites prepared from agrowaste and HDPE. Polymer-Plastics Technology and Engineering 44(3): 511-522.

Patil, Y. P.; Gajre, B.; Dusane, D.; Chavan, S.; Misha, S. 2000. Maleic anhydride treatment on steam and water absorption of wood polymer composites prepared from wheat straw, cane bagasse, and teak wood sawdust using novolac as matrix. J. Applied Polymer Science 77(13): 2963-2967.

Rowell, R. M.; Ellis, W. D. 1977. Determination of dimensional satabilization of wood using the watersoak method. Wood Fiber Sci. 10(2): 104-110.

Rowell, R. M. 2005. Moisture properties. In: Handbook of Wood Chemistry and Wood Composites, Rowell, R. M. (ed.), CRC Press, Inc, Boca Raton, FL, Ch 4.

Sahin, H. T. 2007. The use of Arrhenious kinetic model to predict activation energies in hardwoodwater systems. Surface Review and Letters 14(5): 999-1005.

Sahin, H. T. 2008a. Wood-water interactions as affected by chemical constituents of woods. Asian Journal of Chemistry 20(4): 3267-3276.

Sahin, H. T. 2008b. Application of various solvent-type alkyd resins to pine and cedar woods for achieving water repellence. Pigment \& Resin Technology 37(6): 395-401.

Siau, J. F. 1984. Transport processes in wood. Springer-Verlag, Berlin, Germany

Simpson, W.T. 1993. Specific gravity, moisture content, and density relationship for wood. USDA Forest Service General Technical Report FPL-GTR-76, Madison, WI, USA.

Wegner, T.H.; Winandy, J.E.; Ritter, M.A. 2005. Nanotechnology opportunities in residential and non-residential construction. In: 2nd International Symposium on Nanotechnology in Construction. Bilbao, Spain, pp. 23-31.

Wegner, T.H.; Jones, P. 2006. Advancing cellulose-based nanotechnology. Cellulose 13: 115-118. 